DOI: $10.1590 / 1089-6891 v 20 \mathrm{e}-55398$

MEDICINA VETERINÁRIA

\title{
PICROSIRIUS RED AND MASSON'S TRICHROME STAINING TECHNIQUES AS TOOLS FOR DETECTION OF COLLAGEN FIBERS IN THE SKIN OF DOGS WITH ENDOCRINE DERMATOPATHOLOGIES
}

\section{PICROSIRIUS RED E TRICRÔMICO DE MASSON COMO FERRAMENTAS PARA DETECÇÃO DE FIBRAS COLÁGENAS EM PELE DE CÃES COM DERMATOPATOLOGIAS ENDÓCRINAS}

\author{
Glícia Meneses Costa1 ORCID http://orcid.org/0000-0001-6498-5337 \\ Steffi Lima Araujo ${ }^{1}$ ORCID http://orcid.org/0000-0001-7953-0570 \\ Francisco Antônio Félix Xavier Júnior ${ }^{1}$ ORCID http://orcid.org/0000-0002-2635-1306 \\ Glayciane Bezerra de Morais ${ }^{1}$ ORCID http://orcid.org/0000-0002-3627-7939 \\ João Alison de Moraes Silveira² ORCID http://orcid.org/0000-0002-4502-1214 \\ Daniel de Araújo Viana ${ }^{3}$ ORCID http://orcid.org/0000-0002-0505-5700 \\ Janaina Serra Azul Monteiro Evangelista ${ }^{*}$ ORCID http://orcid.org/0000-0002-9583-1573 \\ ${ }^{1}$ Universidades Estadual do Ceará, Fortaleza, CE, Brazil. \\ Universidade Federal do Ceará Fortaleza, CE, Brazil. \\ ${ }^{3}$ Laboratório PATHOVET - Anatomia Patológica e Patologia Clínica Veterinária LTDA, Fortaleza, CE, Brazil. \\ *Correspondent author - janainaserrazul@gmail.com
}

\begin{abstract}
Canine endocrinopathies, such as hypothyroidism and hyperadrenocortism,induce typical dermatological alterations. Collagen fibers are significant for the maintenance of structural integrity,as well as in the determination of tissue function. This study aimed at assessing the coloration caused by Picrosirius Red staining under circular polarization and Masson Trichrome staining, as tools to quantify the total collagen in the skin of dogs exhibiting endocrine dermatopathies. Skin samples taken from dogs with hypothyroidism and hyperadrenocorticism were stained using Hematoxylin and Eosin (HE), Masson's Trichrome (MT) and Picrosirius Red (PSR). The animals with hyperadrenocorticism revealed a higher percentage of collagen area than did the animals with hypothyroidism PSRp (hypothyroidism $=43.76 \pm 0.8255$ and hyperadrenocorticism $=47.08 \pm 0.8584$ ). The percentage of the collagen area using MT between the groups is given in parenthesis (hypothyroidism $=52.06 \pm$ 0.9371 , hyperadrenocorticism $=61 \pm 0.7529$ and control $=56.88 \pm 0.64)(\mathrm{p}<0.05)$. It is therefore, evident that the special stains employed are useful in estimating the percentage of collagen area in the skin, as they revealed that dogs with hypothyroidism had lower collagen deposition whereas those animals with hyperadrenocorticism showed higher quantity of collagen in the dermis.
\end{abstract}

Keywords: canine endocrinopathies, skin, fibrosis,Picrosirius Red, polarization

\section{Resumo}

Endocrinopatias caninas como hipotireoidismo e o hiperadrenocortismo causam alterações dermatológicas características. As fibras de colágeno desempenham um papel vital na manutenção da integridade estrutural e também na determinação da função dos tecidos. O objetivo deste estudo foi avaliar as colorações de picrosirius red sob polarização circular e coloração tricômio de Masson como ferramentas para quantificar o colágeno total da pele de cães com dermatopatias endócrinas. Amostras de pele obtidas de cães com hipotireoidismo e hiperadrenocorticismo foram coradas por 
Hematoxilina e Eosina (HE), Tricrômio de Masson (MT) e Picrosirius red (PSR). A porcentagem de área de colágeno foi maior nos animais com hiperadrenocorticismo e menor nos animais com hipotireoidismo PSRp (hipotireoidismo $=43,76 \pm 0.8255$ e hiperadrenocorticismo $=47,08 \pm 0.8584$ ) . Já a porcentagem de área de colágeno no MT entre os grupos (hipotireoidismo $=52,06 \pm 0.9371$, hiperadrenocorticismo $=61 \pm 0,7529$ e controle $=56,88 \pm 0.64)(\mathrm{p}<0.05)$. Concluiu-se que as colorações especiais utilizadas são úteis para avaliar a porcentagem de área de colágeno na pele, pois demonstraram que cães com hipotireoidismo demonstraram uma diminuição na deposição de colágeno e os animais com hiperadrenocorticismo apresentaram maior quantidade de colágeno na derme.

Palavras-chaves: hipotireoidismo; hiperadrenocorticismo; fibrose; colágeno.

Received on: October, 11th, 2018.

Accepted on: June 16th, 2019.

\section{Introduction}

Canine endocrinopathies can result in characteristic dermatological changes, like symmetrical bilateral alopecia, hyperpigmentation and absence of pruritus, which can be observed in dogs affected by hypothyroidism and hyperadrenocorticism ${ }^{(1)}$. Hypothyroidism is the most frequently observed effect of endocrinopathy in dogs, while hyperadrenocorticism is another common condition in these animals $^{(2,3)}$.

Cutaneous biopsy reveals findings indicating the presence of hormonal dermatoses such as orthokeratotic hyperkeratosis, follicular dilatation and atrophy, predominantly telogenic hair follicles, sebaceous gland atrophy, epidermal melanosis, and excessive trichilemmal keratinization ${ }^{(4-7)}$. Varying degrees of inflammation, acanthosis, parakeratosis, epidermal or folliculitis were observed in the histopathology of the hypothyroid animals ${ }^{(6)}$.

Some dogs with hypothyroidism showed histologic evidence of myxedema (separation of the dermal collagen fibers accompanied by the deposition of an amorphous basophilic mucin-like material) ${ }^{(5)}$. Collagen fibers play an important part in the maintenance of structural integrity and tissue function determination ${ }^{(8)}$ because collagen is the chief constituent of the dermis of the skin of adult dogs ${ }^{(9)}$.

Normally, Masson's Trichrome stain and other types of trichrome are used to detect the collagen fibers in tissue sections; however, as these methods are not very accurate in highlighting the very thin collagen fibers under certain situations, they result in a substantial underestimation of the collagen content in the sample ${ }^{(10)}$. Trichrome stains show a tendency to fade ${ }^{(11)}$. Therefore, Picrosirius Red (PSR) was recommended for collagen staining because it does not fade for at least a few months. The fine collagen fibers stained more intensely with the PSR stain and increased with polarization ${ }^{(12)}$.

This study aimed at assessing the effectiveness of Picrosirius Red under circular polarization, and Masson's Trichrome (MT) staining, as tools to quantify the total collagen of the skin of dogs affected by endocrine dermatopathies.

\section{Materials and methods}

In this study,an analysis was done of 24 dogs, without racial predisposition and of varying ages, 
categorized under three groups of eight dogs each: the first group with hypothyroidism (HT), the second group with hyperadrenocorticism (HA) and a control group with healthy dogs (CT), diagnosed via clinical and laboratory parameters. These animals included 10 males and 14 females, between 2 and 14 years of age ( $7 \pm 2.5$ years). They were evaluated from March 2016 to March 2017 in the Veterinary Hospital from the State University of Ceará and private veterinary clinics, Ceará, Brazil.

All the experiments were conducted in accordance with the Ethical Principles of Animal Experimentation, adopted by the Committee on Ethics in Animal Use of the State University of Ceara, and approved on March 17, 2017 (Protocol 1534880/2016 - Memo no. 11585871-7/10). All data were anonymously analyzed. The dog owners gave signed written consent.

The inclusion criteria included clinical and laboratory evaluations. Dogs with comorbidities such as dyslipidemia or hepatopathies were excluded from the study, as well as drugs that would interfere in hormonal tests.

The animals belonging to the HT group were subjected to Thyroid-Stimulating Hormone (TSH) and reference values $>0.5 \mathrm{ng} / \mathrm{mL}$ and free thyroxine (T4L) of $<0.82 \mathrm{ng} / \mathrm{dL}$, were considered positive (30). The HA group was submitted to the ACTH stimulation test and a cortisol basal value of $>4.0 \mu \mathrm{g} / \mathrm{dL}$ and cortisol 1-hour post ACTH of $>20 \mu \mathrm{g} / \mathrm{dL}$ were considered positive(31).

The samples were collected via skin biopsies from the skin of the dogs in all the groups. The collected samples were then fixed in $10 \%$ buffered formalin and processed using the standard histological processing techniques. The sections $(4 \mu \mathrm{m})$ were stained with Hematoxylin and Eosin (HE), Masson's Trichrome (MT) and Picrosirius Red (PSR) modified technique by Constantine and Mowry ${ }^{(12)}$. The slides were analyzed under light microscopy.

The cutaneous collagen deposition per field area was quantitatively analyzed using the modified technique by Morais et al. ${ }^{(13)}$. The tissue sections stained by MT and PSR were morphometrically studied using the NIS-Elements software version 4.2. The skin sections stained by PSR were analyzed separately under polarized light.

Random fields $(\mathrm{n}=10)$ from the skin samples of each slide stained by PSR $(100 \times)$ were captured with circular polarization $\left(\right.$ Nikon ${ }^{\circledR}$ Eclipse CiPOL microscope with an attached Nikon DS-Ri2 digital camera). Digital images of histological sections stained by MT were captured employing the standard protocol $(100 \times)$ using a trinocular microscope $\left(\right.$ Nikon ${ }^{\circledR}$ Eclipse Ni with an attached Nikon ${ }^{\circledR}$ DS Rilcamera).

The images thus captured (TIFF format; 1608 x 1608 pixels) were studied to quantify the collagen present in the skin samples of the dogs affected by endocrine dermatopathologies. After the initial arithmetic subtraction of the background lighting was done, the images were readjusted according to the RGB Stack Model Software. These images were then adjusted by the threshold tool and the areas corresponding to the cutaneous collagen deposition were delimited followed by quantification of the average intensity per delimited area in each analyzed field.

The collagen area, obtained via pixels, of each captured image was calculated and expressed as a percentage of the total area imaged. The percentages of the total area quantified in 10 random fields for each skin biopsy from each animal were obtained using the mathematical formula, $\mathrm{R}$ areas quantified $\% / 10$. All measurements were automatically transferred to a Microsoft Excel ${ }^{\circledR} 2016$ spreadsheet and subjected to statistical analysis.

This technique was aimed at distinguishing birefringent (bright) from birefringent (dark) materials. 
The skin color images thus captured were binarized (black and white). The birefringent regions that corresponded to positive staining (collagen) were converted to white. A threshold was set and the black areas were excluded; the volume of the remaining white area was quantified in relation to the field area captured ${ }^{(13)}$ (Figure 1).

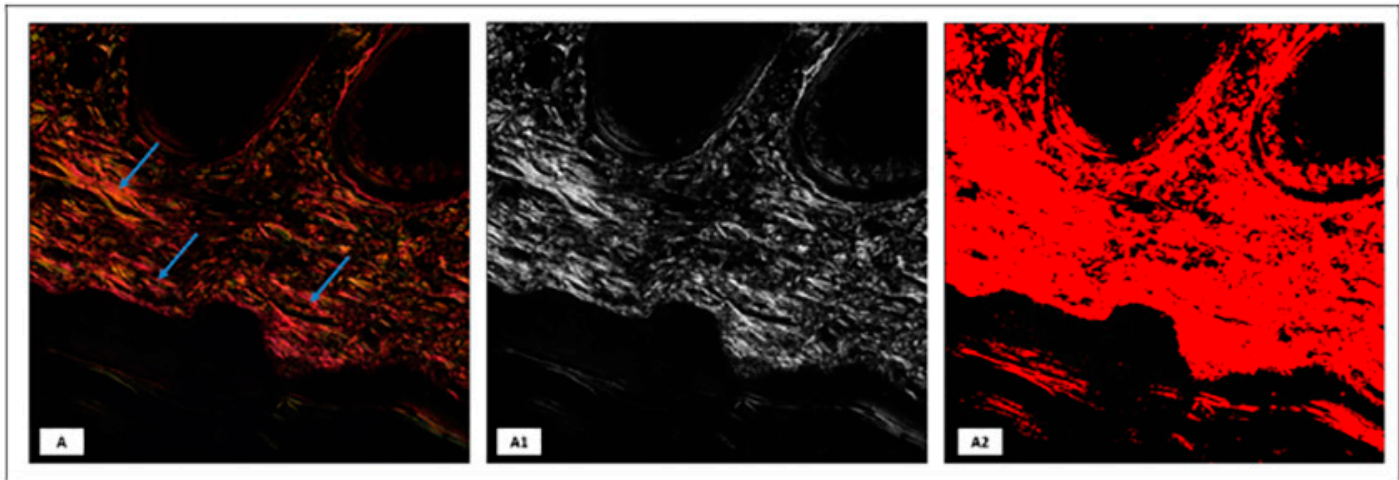

Figure 1. Digital analysis of the lateral trunk skin sections from the dogs with hypothyroidism and hyperadrenocorticism. Representative epidermal-dermal junction in circular polarization. (A)Polarized image depicting the deposit of the birefringent collagen (arrows). (A1) Binarized image. (A2) Regions marked in red corresponding to the collagen deposition in polarization. Picrosirius Red under polarization $10 \times$.

Data were expressed as the mean and standard error of means $(p<0.05)$ and analyzed using the statistical software GraphPad Prism ${ }^{\circledR}$ v7.04 (GraphPad Software, CA, USA). In the evaluation of the collagen area, all the Tables and graphs were drawn-up according to the staining method utilized and the data summary of each animal. Differences between the animal status under the MT and PSRp techniques were compared using the One-Way ANOVA followed by Tukey post-test. The statistical analysis was also used to quantify the total collagen area by the regression model with Spearman's correlation coefficient and values of $\mathrm{p}<0.05$.

\section{Results}

The dogs in the control revealed normal epidermal thickness. Some animals presented areas of epidermal hyperkeratosis and mild epidermal pigmentation. Most of the hair follicles were in the telogen phase (Figure 2).

Dogs with hypothyroidism exhibited hyperpigmentation and caudal alopecia (7 dogs; 87.5\%). All the dogs presented increased thickening of the epidermis. This group showed concomitant clinical evidence of seborrhea (scales, crusts, and rancid odor, but without pruritus). The histopathological skin sections of the dogs with hypothyroidism showed irregular acanthosis with areas of orthokeratosis and parakeratosis that reached the light microscopy of the hair follicles, forming keratin plugs (comedones). Vacuolization of the pilo-erector muscles was observed in $6(75 \%)$ dogs with hypothyroidism (Figure 2 ). The dermis presented inflammatory infiltrate distributed mainly in the superficial dermis, composed mainly of mast cells.

The dogs with hyperadrenocorticism showed areas of alopecia; however, with varying degrees of alopecia and hyperpigmentation. Abdominal distention and striae were the other features observed in these animals. All the dogs revealed epidermal atrophy and hyperkeratosis. Excessive trichilemmal keratinization, follicular dystrophy or follicular atrophy and sebaceous gland atrophy were evident in this dog group. Mineralization of the dermal collagen (calcinosis cutis) was observed in 4 dogs (50\%) 
with an inflammatory infiltrate surrounding it, mainly composed of mast cells (Figure 2).

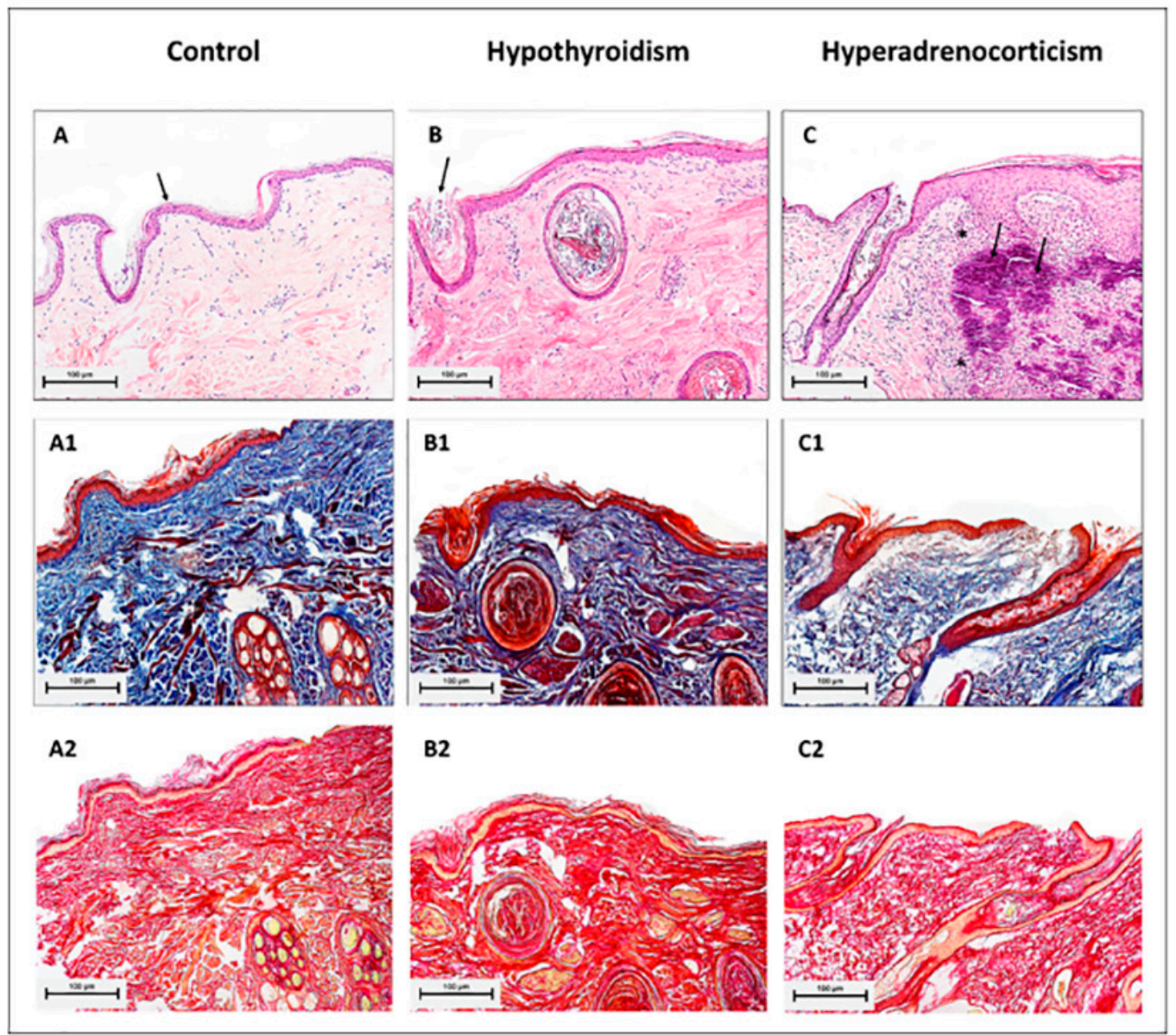

Figure 2. Photomicrographs of the lateral trunk skin from the control dogs and those with hypothyroidism and hyperadrenocorticism. The epidermal-dermal junction from the dogs with normal skin, hypothyroidism skin, hyperadrenocorticism skin in A, B and C, respectively. (A) Control dogs showed normal epidermal thickness (arrow). (B) Dogs with hypothyroidism displayed discrete acanthosis with areas of orthokeratosis and parakeratosis that reached the light microscopy of the hair follicles, forming keratin plugs (comedones - thin arrow).(C) Dogs with hyperadrenocorticism demonstrated mineralization of the dermal collagen (calcinosis cutis- thick arrows) with surrounding inflammatory infiltrates(asterisk). (A,B,C) Hematoxylin and Eosin, (A1,B1,C1) Masson's Trichrome and (A2,B2,C2) Picrosirius Red, 10×.

The quantitative analysis of the percentage of the collagen area found in the skin of dogs having hypothyroidism and hyperadrenocorticism,in comparison to the control dog group (CT $=40.9$ \pm 0.9759 ) using the Picrosirius Red staining technique under polarized light (Figure 3)showed a significant statistical difference in the dogs with hypothyroidism and hyperadrenocorticism $(\mathrm{p}<0.05)$. In this study, using polarized light microscopy with birefringence, the presence of collagen fibers was suggested(Figure 4A). Higher quantification of the percentage of collagen area was observed in the endocrinopathic animals $(\mathrm{HT}=43.76 \pm 0.8255$ and $\mathrm{HA}=47.08 \pm 0.8584)$.

Using Masson's Trichrome staining, the findings of this study showed a statistically significant percentage of the dermal collagen area in the dogs with the endocrinopathies, hypothyroidism and hyperadrenocorticism $(\mathrm{p}<0.05)$, when compared to the control animals $(\mathrm{HT}=52.06 \pm 0.9371 ; \mathrm{HA}=$ $61 \pm 0.7529$ and control $=56.88 \pm 0.64)($ Figure 4B) . 

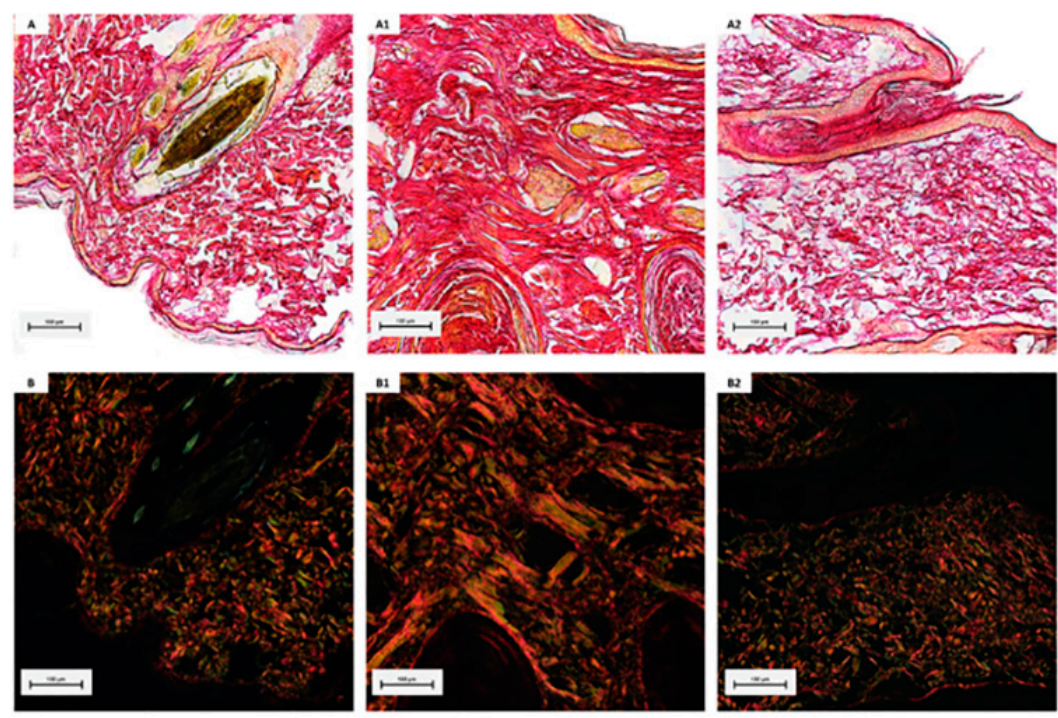

Figure 3. Photomicrographs of the lateral trunk skin from the control, hypothyroidism and hyperadrenocorticism dog groups (B, B1, B2). Under polarization, birefringence is observed in reddish-pink (type I collagen fibers) and green colors (type III collagen fibers). Photomicrographs B, B1, B2 show the same area under polarized light. Picrosirus Red 10×.
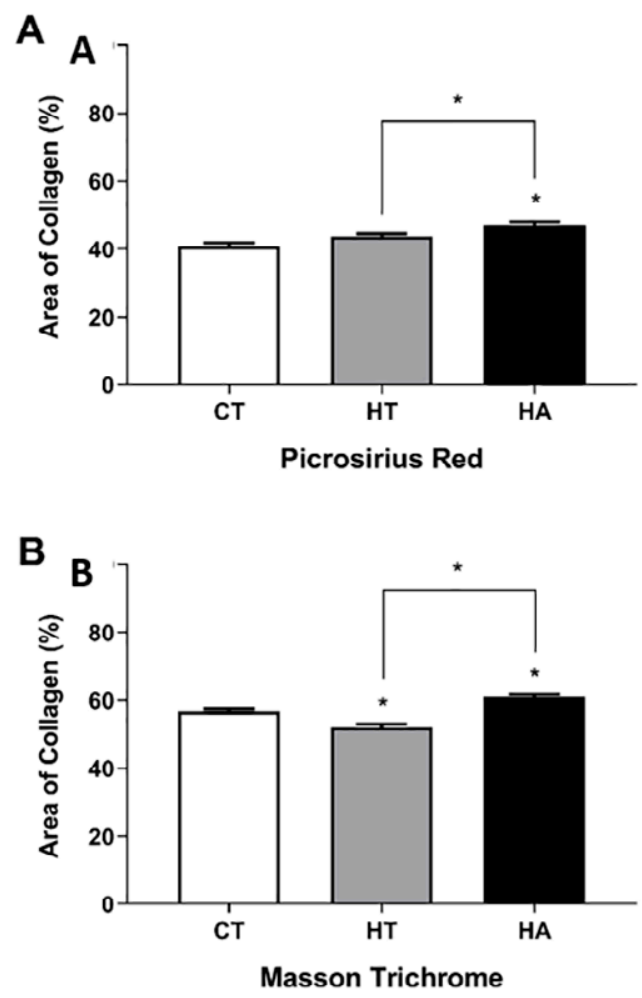

Figure 4. Percentage of the collagen area found in the skin of dogs with hypothyroidism (HT) and hyperadrenocorticism (HA)in comparison to those of the control (CT) group. (A)A significant difference was observed between the CT and HA groups, as well as between the groups with the endocrinopathies (HT and HA), using the Picrosirius Red staining technique under polarized light ( $p<$ 0.05 ). (B)A significant difference was evident between the $\mathrm{CT}$ group and the groups with the endocrinopathies (HT and HA). A marked difference was also observed between the HT and HA groups using Masson's Trichrome stain $(p<0.05)$.

Using Masson's Trichrome staining, the findings of this study showed a statistically significant percentage of the dermal collagen area in the dogs with the endocrinopathies, hypothyroidism and hyperadrenocorticism $(p<0.05)$, when compared to the control animals ( $\mathrm{HT}=52.06 \pm 0.9371 ; \mathrm{HA}=$ $61 \pm 0.7529$ and control $=56.88 \pm 0.64)($ Figure $4 \mathrm{~B})$. 


\section{Discussion}

This study is the first to visualize and quantify the collagen in the skin of dogs with hypothyroidism and hyperadrenocorticism, and compare these results with the skin of healthy dogs.

In this work, the histopathological findings of the dogs with hypothyroidism and hyperadrenocorticism are compatible with those described for hormonal dermatosis ${ }^{(4-7)}$. These authors described sebaceous gland atrophy, epidermal melanosis, excessive trichilemmal keratinization, orthokeratotic hyperkeratosis, follicular dilatation and atrophy and predominantly hair follicles in the telogen phase.

The results revealed that dogs with hyperadrenocorticism showed atrophy of the sebaceous glands, as demonstrated by Outerbridge ${ }^{(5)}$. The histopathological findings of dogs affected by hyperadrenocorticism and hypothyroidism revealed the presence of comedones ${ }^{(4)}$, similar to the findings of this research. This study also showed $50 \%$ of the dogs of this study revealed mineralization of the dermal collagen (calcinosis cutis). The presence of excess of glucocorticoids is significant for the formation of calcinosis cutis. Probably, the most impressive dermatological finding that may be seen as an important signal, but it was not always present in the dogs with typical hyperadrenocorticism ${ }^{(33)}$.

The biochemical properties and morphopysiological skin characteristics were based on the deposition of collagen types I, III and V, which co-assembled into a unique macromolecule to form the heterotypical fibers ${ }^{(14,15)}$. The absolute value of the quantity of the collagen is crucial because skin biopsy is normally used as a diagnostic procedure and can reveal the degree of collagen accumulation in the histopathologic features of the dermis ${ }^{(16)}$.

Morphological changes in collagen fibrils have been described from the quantitative data revealed at different sites, and under several different circumstances, including normal growth ${ }^{(17)}$, changes induced by anabolic steroids ${ }^{(18)}$, ageing ${ }^{(19)}$ and repair ${ }^{(20)}$. Morphological abnormalities of the collagen have also been demonstrated as a characteristic of various types of dysplasia, including systemic sclerosis ${ }^{(21)}$ and spartylglycosuria ${ }^{(22)}$.

As thyroid hormones normally stimulate fibroblast proliferation and collagen synthesis, they affect skin thickness by regulating the synthesis and catabolism of the glycosaminoglycans. The absence of the thyroid hormones results in a lowered fibroblast activity and therefore, in altered collagen metabolism. Cutaneous wounds thus will heal more slowly and in areas subject to trauma, excessive deposition of fibrous tissue may be observed in the normal tissue ${ }^{(32)}$.

Reports in the literature reveal the presence of dermatologic changes in dogs with hyperadrenocorticism because the glucocorticoids inhibit fibroblast proliferation and collagen production ${ }^{(7)}$. Frank ${ }^{(33)}$ concluded that a general decline in the dermal thickness was evident in association with a drop in the fibrillarity, and a rise in the amorphous nature of the thick collagen fibers of the reticular dermis in the skin of dogs with hyperadrenocorticism. In our study, the animals with hyperadrenocorticism revealed a higher quantification of the percentage of the collagen area in the lateral trunk skin, compared to healthy dogs. This higher percentage of collagen observed in this study may be due to the healing process of the dermatological lesions, secondary to the hyperadrenocorticism noted in the animals under study ${ }^{(5)}$.

In this work, PSR with circularly polarized light and MT were used to assess the collagen content. However, the findings of the present study do not concur with the report of Constantine and Mowry ${ }^{(12)}$. These authors demonstrated that the sections stained by PSR under polarization facilitated the 
distinction of and highlighted the thin fibers from the collagen deposition in the fibrotic regions, as well as increased the fiber refrangibility in polarization. In their study, Picrosirius Red did not impart birefringence to the structures that normally lack it. This helps to distinguish the collagen from the other substances that also get stained by the Picrosirius Red. Despite the limitations documented, staining methods such as Van Gieson's and the different forms of trichrome are still in use, as specific for collagen. Many published reports that employed PSR staining for collagen used it in combination with polarized light, while some studies utilized bright-field illumination to detect the collagen ${ }^{(23-25)}$. However, when this approach was used, either the collagen fiber color or brightness was uniform; while the thicker fibers appeared deep red, the thin fibers appeared bright pink and the latter could be difficult to see ${ }^{(26)}$. Some studies used a computer-generated conversion of the original color image to a black-and-white image based on the assignment of the positive (red) collagen staining to white. The non-collagen area and interstitial space were assigned black color, to avoid any error in the attempt to quantify collagen content ${ }^{(24)}$. This approach has the potential of under estimating the collagen content, especially in the tissues that contain large quantities of thin fibers and thus cannot provide an accurate assessment of the collagen content.

Rich \& Whittaker ${ }^{(26)}$ emphasized the ability of the circularly polarized light to reveal structural detail and extend the initial application (collagen content measurement) to the assessment of the color and spatial distribution of fibers. They demonstrated that the combination of Picrosirius Red staining, circularly polarized light, and hue analysis is a powerful tool to analyze collagen fibers.

The MT techniques normally stain the collagen fibers very intensely; however, other areas such as the basal membrane are not selectively stained. They do not enable the differentiation of these structures during quantification, particularly when very thin collagen fibers are present, which could reveal different colors in the same tissue section ${ }^{(12 ; 27-29)}$. The histological staining with Masson's Trichrome permits the quantitative visualization and analysis of the collagen fibers in the connective tissue, turning all these fibers blue in color; however, a background stained red by the dye often poses a challenge to distinguish between the true colors observed ${ }^{(28)}$.

\section{Conclusion}

The conclusion has been drawn that the special stains employed were useful in evaluating the percentage of collagen area in the skin, and they demonstrated that dogs with hypothyroidism showed decrease of collagen deposition, while the animals with hyperadrenocorticism displayed higher quantities of collagen in the dermis.

\section{References}

1. Scarampella F. Alopecia Endócrina no Cão. Veterinary Focus. 2011; 21: 40-46.

2. Ettinger SJ, Feldman EC. Textbook of Veterinary Internal Medicine. 7th ed. St Louis: Saunders; 2010.2208p.

3. Kooistra HS, Galac S. Recent Advances in the Diagnosis of Cushing's Syndrome in Dogs. Vet Clin Small Anim. 2009; 4: 259-67.

4. Müntener T, Schuepbach-Regula G, FranK L, Rüfenacht S, Welle MM. Canine noninflammatory alopecia: a comprehensive evaluation of common and distinguishing histological characteristics. Vet Dermatol. 2012; 23: $206-44$.

5. Outerbridge C.A. Cutaneous Manifestations of Internal Diseases. Vet Clin Small Anim. 2013; 43: 135-152. 
6. Scott DW. Histopathologic findings in endocrine skin disorders of the dog. J Am Anim Hosp Assoc.1982; 18: $173-83$.

7. Scott DW, Miller DH, Griffin CE. Muller \& Kirk - Small animal dermatology. 6th.ed. Philadelphia: Saunders; 2001.1552p.

8. Whittaker P, Boughner DR, Kloner RA. Role of collagen in acute myocardial infarct expansion. Circulation.1991;84: 2123-34.

9. Miller EJ. Biochemical characteristics and biological significance of the genetically distinct collagens. Molec Cell Biochem. 1976; 13:165-92.

10. Kiernan JA. Methods for connective tissue. In: Arnold H, editor. Histological and Histochemical Methods: Theory and Practice. 3rd ed. Oxford, UK: Butterworth-Heinemann;1999. p.144-63.

11. Sweat F, Puchtler H, Rosenthal SI. Sirius red F3BA as a stain for connective tissue. Arch Pathol. 1964; 78: 69-72.

12. Constantine VS, Mowry W. Selective staining of human dermal collagen. J InvestDermat. 1968; 50(5), 414-18.

13. Morais GB, Viana DA, Silva FMO, Xavier Júnior FAF, Farias KM, Pessoa CD’Ó, Silveira JAM, Alves APNN, Mota MRL, Silva FDO, et al. Polarization microscopy as a tool for quantitative evaluation of collagen using picrosirius red in different stages of CKD in cats. Microsc Res Tech.2017; 80, 543-50.

14. Gelse K, Poschl E, Aigner T. Collagens: strutcture, function and byosynthesis. Adv Drug Deliv Rev. 2003; 55: $1531-46$.

15. Birk DE, Fitch JM, Babiarz JP, Doane KJ, Linsenmayer TF. Collagen fibrillogenesis in vitro: interaction of types I and V collagen regulates fibril diameter. J Cell Sci. 1990; 95: 649-57.

16. Martin P, Teodoro WR, Velosa APP, Morais J, Carrasco J, Christmann RB, Goldenstein-Schainberg C, Parra ER, Katayama ML, Sotto MN, et al. Abnormal collagen V deposition in dermis correlates with skin thickening and disease activity in systemic sclerosis. Autoimmun Rev. 2012; 11: 827-35.

17. Moore MJ, De Beaux A. A quantitative ultrastructural study of rat tendon from birth to maturity. J Anat. 1987; 153: 163-69.

18. Michna, H.Organisation of collagen fibrils in tendon: changes induced by an anabolic steroid. Virchows Arch A.1986;52: 87-8.

19. Breiteneder-Geleff S, Mallinger R, Bock P. Quantitation of collagen fibril cross section profiles in ageing human veins. Hum Pathol. 1990; 21: 1031-35.

20. Wilson K, Moore MJ, Rayner CR, Fenton OM. Extensor tendon repair: an animal model which allows immediate post-operative mobilisation. J Hand Surg B. 1990; 15: 74- 8.

21. Pasquali RI, Guerra D, Quaglino D Jr, Vincenzi D, Manzini E, Canossi B, Manzini CV. Dermal elastin and collagen in systemic sclerosis. Effect of D-penicillamine treatment. Clin Exp Rheumatol. 1989; 7: 373-83.

22. Näntö-Salonen K, Pelliniemi LJ, Autio S, Kivimäki T, Rapola J, Penttinen R. Abnormal collagen fibrils in aspartylglycosuria. Altered dermal ultrastructure in a glycoprotein storage disorder. Lab Invest. 1984; 51: 464-68.

23. Moon JCC, Reed E, Sheppard MN, Elkington AG, Ho SY, Burke M, Petrou M, Pennell DJ. The histologic basis of late gadolinium enhancement cardiovascular magnet ic resonance in hypertrophic cardiomyopathy. J.

Cienc. anim. bras., Goiânia, v.20, 1-10, e-55398, 2019 
Am. Coll.Cardiol. 2004; 43: 2260-64.

24. Nart P, Williams A, Thompson H, Innocent GT. Morphometry of bovine dilated cardiomyopathy. J. Comp. Pathol. 2004; 130: 235-45.

25. Ophof R, Maltha JC, Von den Hoff JW, Kuijpers-Jagtman AM. Histologic evaluation of skin-derived and collagen-based substrates implanted in palatal wounds. Wound Repair Regen. 2004; 12: 528-38.

26. Rich L, Whittaker P. Collagen and picrosirius red staining: a polarized light assessment of fibrillar hue and spatial distribution. Braz J Morphol Sci. 2005; 22(2): 97-104.

27. Montes GS, Junqueira LCU. The use of the picrosiriuspolarization method for the study of the biopathology of collagen. Mem Inst Oswaldo Cruz .1991; 86: 1-11.

28. Street JM, Souza ACP, Alvarez-Prats A, Horino T, Hu X, Yuen PST, Star RA. Automated quantification of renal fibrosis with sirius red and polarization contrast microscopy. Physiol Rep. 2014; 2(7): 1-9.

29. Taboga SR, Vidal BC. Collagen fibers in human prostatic lesions: histochemistry and anisotropies. J SubmicroscCytolPathol. 2003; 35:11-16.

30. Scott-Moncrieff. The thyroid gland. In: Feldman E.; Nelson R.; Reusch C.; Scott-Moncrieff JC. Canine e feline endocrinology. 4th ed. Saint Louis, USA: Elsevier; 2015. p.77-132.

31. Peterson, ME. Diagnosis of Hypeadrenocorticism in dogs. Clin Tech Small AnimPract, 2007; 22(2): 2-11.

32. Credille KM, Slater MR, Moriello KA, Nachreiner RF, Tucker KA, Dunstan RW. Thyroid Hormones on the Skin of Beagle Dogs. J Vet Intern Med2001;15: 539-546

33. Frank LA.Comparativedermatology - canineendocrine dermatoses. Clinics in Dermatol. 2006; 24: 317325. 